\title{
Genetic divergence in forage sorghum (Sorghum bicolor L. Moench)
}

\author{
Nishant Kumar Ahalawat ${ }^{1}$, Vichitra Kumar Arya ${ }^{2 *}$, Pradeep Kumar', and Shiv Kumar \\ Singh ${ }^{1}$ \\ ${ }^{1}$ Sardar Vallabhbhai Patel University of Agriculture and Technology, Meerut, 250110 (UP), INDIA \\ ${ }^{2}$ Indian Institute of Wheat and Barley Research, Karnal, 132001 (Haryana), INDIA \\ *Corresponding authors: E-mail: aryavichitra@gmail.com
}

Received: July 31, 2017; Revised received: December 29, 2017; Accepted: February 20, 2018

\begin{abstract}
Thirty genotypes of forage sorghum were studied for generating information on nature and magnitude of genetic variability and diversity for designing breeding programme. The experiment was conducted in randomized complete block design in three replications. The data were recorded on days to $50 \%$ flowering, plant height, leaf breadth, leaf length, leaf area, stem girth, leaves per plant, leaf stem ratio, total soluble solids, protein content and green fodder yield. Analysis of variance revealed a substantial amount of variability among the genotypes for all the characters under study, indicated a wide spectrum of variability among the genotypes. Highest estimates of the phenotypic coefficient of variation and genotypic coefficient of variation were observed for plant height, leaf breadth, leaves per plant, leaf stem ratio and green fodder yield. High heritability coupled with high genetic advance was observed for plant height, leaf area, stem girth, leaves per plant, leaf stem ratio and green fodder yield. Based on $D^{2}-$ Statistics, 30 genotypes were grouped into six clusters. The highest inter-cluster distance was observed between cluster III and VI followed by IV and VI, indicating genotypes included in these clusters had wide genetic diversity. Genetic divergence and cluster mean indicates maximum heterosis and good recombinants may be achieved in crosses between genotypes of clusters III, IV and VI in varietal improvement programme. Thus, crossing between genetically diverse genotypes of cluster III with genotypes CSV 15, PC 1001, SPV 462, PC 3, SSV 84 , PC 8 and cluster VI with genotype HJ 513 are expected to exhibit high heterosis and good recombinants with desired traits.
\end{abstract}

Keywords: $D^{2}$-statistic, Genetic divergence, Green fodder yield, Inter-cluster distance, Sorghum

\section{INTRODUCTION}

Sorghum [Sorghum bicolor (L.) Moench ] is the fifth most important cereal crop after wheat, rice, maize and barley at world level. However, it is the second most important cereal in India according to the cultivated area, although in grain production occupied the third position which is just below the wheat and rice. The grain of sorghum forms a stable food in the diets of the rural people and used as fodder for livestock. Sorghum is cultivated during rainy and post rainy seasons in semi-arid regions of the country on the marginal lands (Elangovan and Babu, 2015). This crop is well adapted to drought-prone regions with poor soil than other cereal crops. In India, it is grown about 6.18 million ha area and production of 5.33 million tones with an average yield of $862 \mathrm{~kg}$ per hectare (Anonymous, 2014). Sorghum is mainly used as fodder for livestock in India. Forage sorghum seems to be a promising option in meeting out the increasing gap between fodder requirement and availability because it bears xerophilic characteristics, wide adaptation, fast growth habit, good ratoonability, palatability and digestibility and diversified uses such as green fodder, dry roughage and silage
(Yadav et al., 2004). Genetic variability is prerequisite in the existing population for varietal improvement. Loss of genetic variability leading to genetic erosion has led to greater emphasis on germplasm collection and characterization for present and future plant breeding programmes (Prasanna, 2010).

Knowledge of genetic diversity of a crop usually helps the breeder in choosing desirable parents for the breeding program and gene introgression from distantly related germplasm. The more diverse genotypes or accessions can be crossed to produce superior hybrids with resistance to abiotic and biotic stresses (Elangovan and Babu, 2015). Understanding the wealth of genetic diversity in sorghum will facilitate the further improvement of this crop for its genetic architecture. Genetic diversity in the crop species is the gift of nature and arises due to geographical separation or due to genetic barriers to crossability. Morphological traits are conventional tools to analyze the genetic diversity (Prasanna, 2010). Morphological assays generally require neither sophisticated equipment nor preparatory procedures. They are generally simple and inexpensive to score. These easily observable quantitative morphological traits are a useful tool for prelimi- 
nary evaluation because they offer a fast and useful approach for assessing the extent of diversity. Over the years, a number of studies have dealt with estimating genetic diversity in cultivated sorghum using morphological traits. The use of morphological traits is the most common approach utilized to estimate relationships between genotypes. The genetic variability of cultivated species/varieties and their wild relatives together form a potential and continued source for the development of improved crop varieties. A better understanding of genetic diversity in sorghum will facilitate crop improvement. Keeping in view, the present study was carried out to determine the extent of genetic diversity among forage sorghum genotypes.

\section{MATERIALS AND METHODS}

The experimental materials consisted of 30 genotypes of sorghum were grown in a randomized block design with three replications at Crop Research Centre of Sardar Vallabhbhai Patel University of Agriculture and Technology, Meerut (U. P.) during kharif 2015. The experiment was sown on 5 June 2015 in a 4-row plot of 5-meter length. The row to row spacing was $30 \mathrm{~cm}$, and plant to plant distance was $10 \mathrm{~cm}$. All cultural practices essential for the good crop of forage sorghum were applied for obtaining healthy and competitive crop strand. The observations were recorded on five randomly selected competitive plants from each genotype in each replication on eleven agro-morphological characters viz; days to $50 \%$ flowering, plant height $(\mathrm{cm})$, leaf breadth $(\mathrm{cm})$, leaf length $(\mathrm{cm})$, leaf area $\left(\mathrm{cm}^{2}\right)$, stem girth $(\mathrm{mm})$, leaves per plant, leaf stem ratio, total soluble solids (\%), protein content $(\%)$ and green fodder yield $(\mathrm{q} / \mathrm{ha})$. The treatment means for all the characters were subjected to compute the analysis of variance on the basis of the model proposed by Panse and Sukhatme (1969). The phenotypic coefficient of variation (PCV) and genotypic coefficient of variation (GCV) was analyzed by adopting the procedure suggested by Searle (1961). Heritability in broad sense $h^{2}$ (b) and genetic advance as per cent of the mean were estimated by the formula as suggested by Allard (1960). Mahalanobis (1936) $\mathrm{D}^{2}$ statistic analysis was used for estimation of genetic divergence among forty-nine genotypes. The clustering of $\mathrm{D}^{2}$ values was formed by using the Tocher's method as described by Rao (1952).

\section{RESULTS AND DISCUSSION}

Genetic variability: The analysis of variance showed highly significant differences for all the traits among the genotypes (Table 1) The high magnitude of variation for the experimental material revealed wider range for all the traits. This suggested the adequate amount of variability among germplasm that may be helpful for trait improvement by selection. The high amount of genetic variability for many of these traits has been

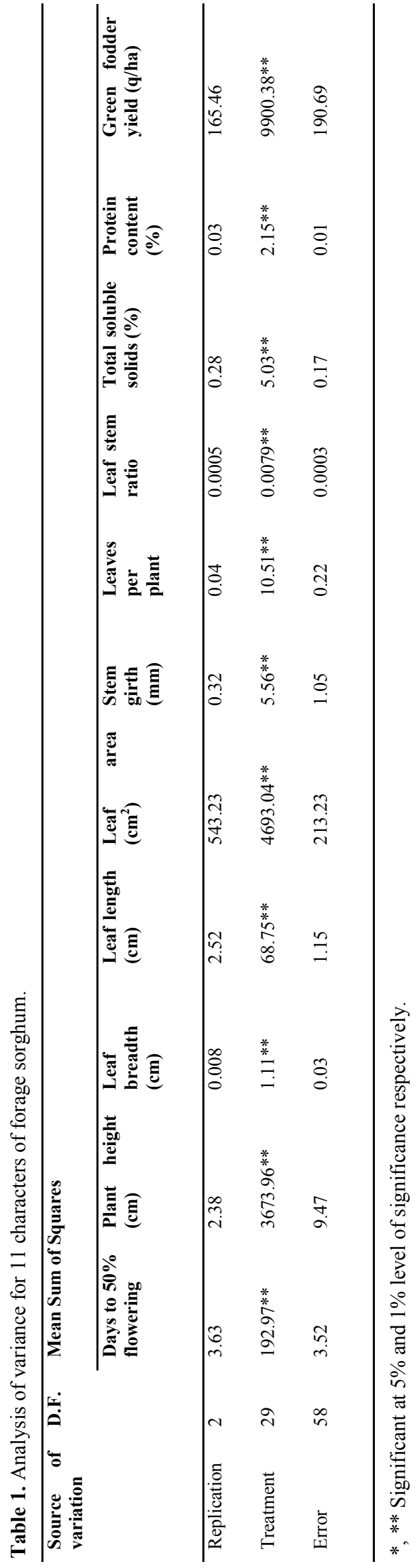


Table 2. Genetic parameters for 11 characters of forage sorghum.

\begin{tabular}{llllll}
\hline \multirow{2}{*}{ Character } & \multicolumn{2}{l}{ Coefficient of variation (\%) } & \begin{tabular}{l} 
Heritability \\
in \\
\cline { 2 - 5 } broad sense
\end{tabular} & $\begin{array}{l}\text { Genetic } \\
\text { advance }\end{array}$ & $\begin{array}{l}\text { GA as percentage } \\
\text { of mean }\end{array}$ \\
\hline Days to 50\% flowering & 9.68 & 9.94 & 94.00 & 15.93 & 17.40 \\
Plant height (cm) & 32.75 & 32.80 & 99.00 & 31.72 & 26.16 \\
Leaf breadth (cm) & 28.56 & 28.97 & 91.00 & 15.18 & 16.84 \\
Leaf length $(\mathrm{cm})$ & 6.58 & 6.74 & 95.00 & 9.54 & 13.21 \\
Leaf area $\left(\mathrm{cm}^{2}\right)$ & 10.72 & 11.46 & 87.00 & 25.46 & 25.66 \\
Stem girth (mm) & 6.77 & 8.84 & 86.00 & 31.93 & 30.68 \\
Leaves per plant & 26.39 & 26.46 & 93.00 & 25.69 & 26.70 \\
Leaf stem ratio & 25.19 & 26.38 & 89.00 & 20.10 & 22.55 \\
Total soluble solids (\%) & 6.09 & 6.96 & 90.00 & 2.49 & 1.46 \\
Protein content (\%) & 1.84 & 1.95 & 97.00 & 1.72 & 4.02 \\
Green fodder yield (q/ha) & 29.05 & 29.96 & 94.00 & 25.89 & 29.38 \\
\hline
\end{tabular}

Table 3. Clustering pattern of 30 forage sorghum genotypes on the basis of $\mathrm{D}^{2}$ cluster analysis.

\begin{tabular}{lll}
\hline Cluster & Genotype & Name of genotypes \\
\hline I & 8 & Rampur local, PC 121, PC 1002, GFS 5, Jalana local, SPV 1616, HC 171, PC 7 \\
II & 13 & PC 23, PC 6, HC 308, CSV 21F, PC 4, Rajasthan local, MP Chari, UP Chari 2, CSV 17, \\
& & Golden Local, PC 615, Gwalior Local, HC 260 \\
III & 6 & CSV 15, PC 1001, SPV 462, PC 3, SSV 84, PC 8 \\
IV & 1 & PC 5 \\
V & 1 & HC 136 \\
VI & 1 & HJ 513 \\
\hline
\end{tabular}

Table 4. Estimates of average inter and intra- cluster distances for 8 clusters of forage sorghum.

\begin{tabular}{lllllll}
\hline Clusters & I & II & III & IV & V & VI \\
\hline I & $\mathbf{1 6 0 . 4 3}$ & 282.95 & 347.20 & 558.90 & 392.15 & 926.31 \\
II & & $\mathbf{1 8 0 . 5 2}$ & 336.26 & 574.63 & 467.83 & 1181.13 \\
III & & $\mathbf{2 0 1 . 7 9}$ & 770.17 & 375.12 & 1625.06 \\
IV & & & $\mathbf{1 9 0 . 0 2}$ & 377.75 & 1606.26 \\
V & & & & $\mathbf{1 9 8 . 6 2}$ & 1555.30 \\
VI & & & & & $\mathbf{3 7 3 . 9 6}$ \\
\hline
\end{tabular}

Diagonal and bold values are intra cluster distances

reported earlier by Khandelwal et al. (2016). The presence of large extent of variability might be due to diverse sources of breeding materials collected as well as environmental effects on phenotypes.

The genetic parameters studied are presented in Table 2 . The magnitude of the phenotypic coefficient of variation (PCV) was greater than the genotypic coefficient of variation (GCV) for all the traits studied mainly due to environmental influence in the expression of the characters. These findings are similar in agreement with earlier reported by Khandelwal et al. (2016). The high amount of GCV and PCV were observed for plant height (32.75 and 32.80) followed by green fodder yield (29.05 and 29.96), leaf breadth (28.56 and 28.97), leaves per plant (26.39 and 26.46) and leaf stem ratio (25.19 and 26.38). Similar results were also reported by Vedansh et al. (2010), Jain and Patel (2014), Malik et al. (2015) and Khandelwal et al. (2016) in sorghum. Moderate estimate of GCV and PCV were exhibited for leaf area (10.72 and 11.46), while, days to $50 \%$ flowering (9.68 and 9.94), leaf length (6.58 and 6.74), stem girth (6.77 and 8.84), total soluble solids (6.09 and 6.96) and protein content (1.84 and 1.95) showed low values of GCV and PCV. This suggested low variability for such traits among geno- types. High magnitude of GCV and PCV for plant height, green fodder, leaf breadth, leaves per plant and leaf stem ratio indicated that fodder yield might be improved through direct selection. However, lower values of GCV and PCV suggested that improvement for such traits might be obtained for some extent and these traits cannot be influenced by the environment as they are very stable traits. Exploitation of such stable traits for generating variability among genotypes is possible.

The proportion of variability inherited from parents to off spring is manifested by heritability (Lush, 1949). The information on the heritability estimates is useful in studying the inheritance of quantitative characters as well as for planning breeding programmes with the desired degree of expected genetic progress. The heritable variation can be found with the help of heritability estimates and genetic gain. The estimation of heritability coupled with a coefficient of variability would mean the amount of advance expected. In this concern, high estimates of heritability in broad sense were observed for all the traits viz., days to $50 \%$ flowering (94), plant height (99), leaf breadth (91), leaf length (95), leaf area (87), stem girth (86), leaves per plant (93), leaf stem ratio (89), total soluble solids (90), pro- 
Nishant Kumar Ahalawat et al. / J. Appl. \& Nat. Sci. 10 (1): 439 - 444 (2018)

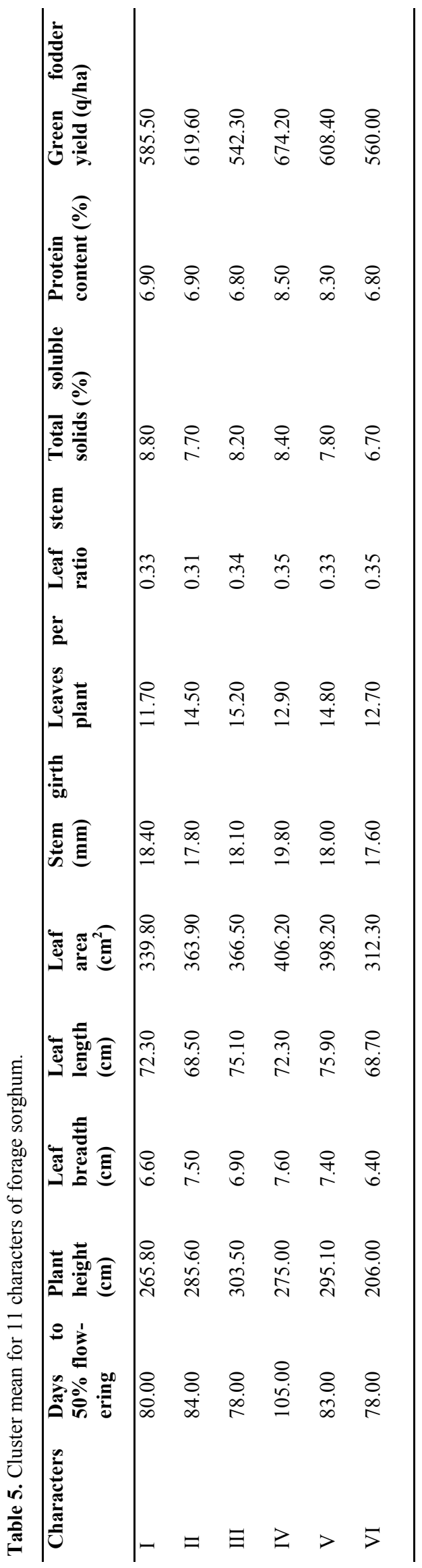

tein content (97) and green fodder yield (94) as depicted in Table 2, indicating that these traits were under genetic control and may be adopted for improving the green fodder yield. The results were in agreement with the findings of Rajguru et al. (2005), Deepalakshmi et al. (2007) and Malik et al. (2015) in sorghum. This shows the presence of additive gene effect and selection may be done for improvement of these traits. However, low heritability exhibited that characters were highly influenced by environmental effect and improvement through selection will be very difficult. The character showing high heritability may not be inevitable impart high genetic advance. The utility of heritability is increased when it is used to estimate genetic advance (Johnson et al., 1955). It can find out with a greater degree of accuracy when heritability coupled with genetic advance is studied (Dudley and Moll, 1969). Therefore, estimation of heritability along with genetic advance is more useful to understand the type of gene action involved in the expression of various polygenic characters. High heritability coupled with high genetic advance as percent mean were revealed for plant height, leaf area, stem girth, leaves per plant, leaf stem ratio and green fodder yield. Similar findings were reported by Khandelwal et al., (2016) and Rana et al., (2016) in sorghum. This indicates the substantial contribution of additive genetic action in the expression of the characters. Hence, direct selection for such traits would be more effective. The traits like leaf length, total soluble solids and protein content exhibited high heritability along with low genetic advance suggested a predominance of non-additive gene action hence; direct selection for such characters would mislead the expected results.

Genetic diversity: Thirty genotypes of forage sorghum were grouped into six clusters based on $\mathrm{D}^{2}$. statistics in such a way that genotypes within a cluster had low $\mathrm{D}^{2}$ values than those of in-between the characters. The composition of clusters has been depicted in Table 3. The distribution pattern of genotypes showed that cluster II had a maximum number of genotypes (13) followed by cluster I (8) genotypes and cluster III (6) whereas, cluster IV, V and VI had a minimum number of genotype (1) respectively. The inter-cluster distance was observed higher than intra-cluster, suggesting wide genetic diversity among genotypes (Table 4). The intra-cluster distance varied from 160.43 to 373.96 whereas inter-cluster distance ranged from 282.65 to 1625.06 . The maximum inter-cluster distance was noticed in the cluster III and VI (1625.06) followed by cluster IV and VI (1606.27), cluster V and VI (1555.30), cluster II and VI (1181.13), cluster I and VI (926.31) and cluster III and IV (770.18). This clearly indicates that genotypes included in clusters III and VI had a broad spectrum of genetic diversity and could be used in hybridization programme of forage sorghum for improving the fodder yield. However, least inter 
cluster distance was observed between clusters I and II (282.95). The lowest inter-cluster distances indicate that the genotypes of these clusters had a close relationship and hence, may not be emphasized upon to be used in hybridization programme. The maximum intracluster distance was observed in cluster VI (373.96), followed by cluster III (201.78) and cluster V (198.62). It was noticed that genotypes within cluster VI with a high degree of divergence would produce more desirable breeding materials for attaining the maximum genetic advance. The minimum intra-cluster distance was registered in cluster I (160.43) followed by cluster II (180.52) and cluster IV (190.02), indicating homogeneous nature of the genotypes with less deviation between the genotypes. Hence selection will be ineffective. Similar results were reported by Shivani and Sreelakashmi (2015) in sorghum.

The cluster mean analyzed for 11 characters under study are presented (Table 5). Days to 50\% flowering showed highest mean values for cluster IV (105) whereas lowest mean values for cluster III (78). Plant height exhibited highest mean for cluster III (303), and lowest mean for cluster VI (206). Leaf breadth revealed highest mean for cluster IV (7.6) and lowest mean for cluster VI (6.4). Leaf length noted highest mean for cluster $\mathrm{V}$ (75.9) and the lowest mean for cluster II (68.5). Leaf area recorded highest mean for cluster IV (406.2), and lowest mean for cluster VI (312.3). Stem girth showed highest mean for cluster IV (19.8) and lowest mean for cluster VI (17.6). Leaves per plant had highest mean for cluster number III (15.2), and lowest mean for cluster I (11.7). Leaf stem ratio revealed highest mean for cluster IV $(0.35)$ and lowest mean for cluster II $(0.31)$. Total soluble solids exhibited highest mean for cluster I (8.8) and lowest mean for cluster VI (6.7). Protein content revealed highest mean for cluster IV (8.5) and lowest mean for cluster VI (6.8). Green fodder yield showed highest mean values for cluster IV (674.2), and lowest mean for cluster III (542.3).

Cluster IV exhibited highest mean values for days to $50 \%$ flowering (105 days), leaf breadth (7.6), leaf area (406.2), stem girth (19.8), leaf stem ratio (0.35), protein content (8.5) and green fodder yield (674.2). Cluster III showed the highest mean for plant height (303.5) with leaves per plant (15.2). However, maximum leaf length and total soluble solids were observed in cluster $\mathrm{V}$ and I (75.9 and 8.8) respectively. The results are in agreement with the findings of earlier workers (Khadakabhavi et al., 2014; Elangovan and Kiranbabu; 2015) for quantitative characters in sorghum. The results from the present study suggest that crossing among genotypes from different clusters exhibiting good mean performance which may be utilized in achieving high yield.

On the basis of divergence and cluster mean, it may be suggested that maximum heterosis and good recombi- nants could be obtained in crosses between genotypes of cluster III, IV and VI in varietal improvement. Thus, crossing between the genetically diverse genotypes of cluster III with genotypes CSV 15, PC 1001, SPV 462, PC 3, SSV 84 and PC 8 and cluster VI with genotypes like HJ 513 are expected to exhibit high heterosis and are also likely to produce new recombinants with desired traits.

\section{Conclusion}

Variability studies suggest that all characters like days to $50 \%$ flowering, plant height, leaf breadth, leaf length, leaf area, stem girth, leaves per plant, leaf stem ratio, total soluble solids, protein content and green fodder yield can be used in hybridization programme for obtaining superior and desired recombinants for particular trait. High heritability coupled with high genetic advance was observed for days to $50 \%$ flowering, leaf area, stem girth, leaves per plant, leaf stem ratio and green fodder yield which may be used as a tool for desired characters in relation to direct selection of superior genotypes from a diverse population. Genotype from the same geographical region fell into different clusters and vice-versa. This suggested that selections of parents for hybridization should be on genetic diversity rather than on the geographical areas. The per cent contribution of plant height followed by green fodder yield, stem girth, leaves per plant, leaf area, leaf length, days to $50 \%$ flowering, leaf stem ratio and leaf breadth contributed most towards genetic divergence. Genetic divergence study suggested that crosses between the genotypes of cluster VI (HJ 513), cluster V (HC 136) and cluster IV (PC 5) and genotypes of cluster III (CSV 15, PC 1001, SPV 462, PC 3,SSV 84 and PC 8) for getting better hybrid vigour in F1 or better hybrids and also for good recombinants in segregating population.

\section{REFERENCES}

Allard, R.W. (1960). Principle of plant breeding. John Wiley and sons. New York, Pp: 185

Anonymous (2014). Agriculture statistics at a glance 2014. Area and production of sorghum, pp: 75-77

Deepalakshmi, A.J. and Ganesamurthy, K. (2007). Studies on genetic variability and character association in kharif sorghum [Sorghum bicolor (L.) Moench]. Indian Journal of Agricultural Research, 41(3): 177-182

Dudley, J.W. and Moll, R.H. (1969). Interpretation and uses of estimates of heritability and genetic advance in plant breeding. Crop Science, (9): 257-262

Elangovan M. and Babu P. K. (2015). Genetic variability and diversity of sorghum land race collected from Uttar Pradesh India. Indian Journal of plant genetic resources, 28(2):213 22

Jain, S.K. and Patel, P.R. (2014). Characters association and path analysis in sorghum (Sorghum bicolor (L.) Moench) and their parents. Annals of Plant and Soil Research, 16 (2): 107-110 
Johnson, H.W., Robinson, H.F. and Comstock, R.E. (1955). Estimation of genetic and environment variability in sorghum. Agronomy Journal, 47: 314-318

Khandelwal, V., Shukla, M., Jodha, B.S., Nathawat, V.S. and Dashora, S.K. (2016). Genetic parameters and character association in sorghum (Sorghum bicolor (L.) Moench) Indian Journal of Science and Technology, 8(22):73-90.

Khadakabhavi, S., Girish, G., Dharmaraj, P. S. and Lokesh, R. (2014). Genetic diversity analysis in germplasm lines of rabi sorghum (Sorghum bicolor (L.) Moench) based on quantitative traits. International Journal of plant science, volume 9, $\mathrm{Pp}: 129-132$

Lush, J.L. (1949). Heritability of quantitative characters in farms animals. Proceedings of 8th Congress of Genetics and Hereditas, 35:356-375

Mahalanobis, P. C. (1936), "On the generalized distance in statistics," Proceedings of the National Institute of Sciences of India, 12, 49-55

Malik, A., Singh, S. K., Chand, P., Singh, B. and Singh, D.K. (2015). Genetic Variability, heritability and Genetic Advance Studies on forage sorghum. Progressive Agriculture, 15 (1) 92-94.

Panse, V.G. and Sukhatme, P.V. (1969). Statistical methods for agricultural workers. Indian Council of Agricultural Research, New Delhi.

Prasanna, B.M. (2010). Phenotypic and molecular diversity of maize landraces: characterization and utilization. The
Indian Journal of Genetics and Plant Breeding, 70:315327

Rana, H.R., Prajapati, K.N., Suthar, K.J. and Kher, H.R. (2016). Study of variability, correlation, and path analysis in Sorghum (Sorghum bicolor (L.) Moench). The Bioscan 11(1): 259-263.

Rajguru, A. B., Kashid, N.V., Kamble, M. S., Rasal, P. N. and Gosavi, A. B. (2005). Gene action and heritability studies in rabi sorghum [Sorghum bicolor (L.) Moench]. Journal of Maharashtra Agricultural Universities, 30(3): 367-368.

Rao, C.R. (1952). Advance statistical methods in biometrical Research Edition I. John Willey and Sons, New York.

Searle, S.R. (1961). Phenotypic, genotypic and environmental correlations. Biometrics 47: 474-480.

Shivani, D. and Sreelakashmi, Ch. (2015). Germplasm evaluation of forage sorghum (Sorghum bicolor (L.) Moench). Journal global biosciences, Pp: 3150-3153.

Vedansh, Singh, S.K., Kerkhi, S. A., Singh, A., Kumar, M. and Kumar, V. (2010). Variability, Heritability and genetic advance for forage yield and quality traits in forage sorghum [Sorghum bicolor (L.) Moench]. Progressive Agriculture, 10 (2): 400-401.

Yadav, R., Grewal, R.P.S. and Pahuja, K.P. (2004). Multivariate analyses in forage sorghum [Sorghum bicolor (L.) Moench]. The Indian Journal of Genetics and Plant Breeding, 64(1): 39-45. 